\title{
Antioxidant activity and protection against oxidative-induced damage of Acacia shaffneri and Acacia farnesiana pods extracts: in vitro and in vivo assays
}

Claudia Delgadillo Puga ${ }^{1 *}$, Mario Cuchillo Hilario1, José Guillermo Espinosa Mendoza ${ }^{3}$, Omar Medina Campos², Eduardo Molina Jijón², Margarita Díaz Martínez', Marsela Alejandra Álvarez Izazaga', José Ángel Ledesma Solano and José Pedraza Chaverri ${ }^{2}$

\begin{abstract}
Background: Obesity is a worldwide public health issue, reaching epidemic condition in developing countries associated to chronic diseases. Oxidative damage is another side effect of obesity. Antioxidant activity from plant components regulates at some extent this imbalance. Main goal of the present study was to determine the antioxidant activity and protection against oxidative-induced damage of Acacia shaffneri (AS) and Acacia farnesiana (AF) pods extracts.

Methods: To evaluated antioxidant activity and radical scavenging capacity of AS and AF extracts, two experiments were performed: 1) pods extracts were challenged against $\mathrm{H}_{2} \mathrm{O}_{2}$ using kidney cells in an in vitro assay; and 2) (Meriones unguiculatus) was employed in an in vivo assay to observe the effect of pods extracts on scavenging properties in plasma.

Results: Both pods extracts presented an important protective effect on radical scavenging capacity against ABTS. + and $\mathrm{DPPH}^{+}$, and also in TBARS formation in vitro. Vegetal pods extracts did not induce any pro-oxidative effect when added to kidney cells in DMEM. Cells damage in DMEM with addition of $\mathrm{H}_{2} \mathrm{O}_{2}$ was significantly higher than those when vegetal pods extracts were added at $50(P<0.05)$ or 200 ppm $(P<0.001)$. Plasma scavenging properties presented an important dose-dependent positive effect in those groups where pods extracts were administered.

Conclusions: The antioxidant protection of the acacia pods extracts reported in this study suggests the possible transference of antioxidant components and protective effects to animal products (milk, meat, and by-products) from Acacia pods when this vegetation is included in the diet. In order to evaluate, the possible transference of theirs antioxidant components to animal products, the incorporation of these non-conventional resources to ruminant feeding is a good opportunity of study. Profiling of Acacia farnesiana pods extract is necessary to identify the responsible bioactive compounds of protective properties.
\end{abstract}

Keywords: Acacia pods, Antioxidant activity, Damage protection, Free radicals

\footnotetext{
* Correspondence: claudia.delgadillop@incmnsz.mx

'National Institute of Medical Science and Nutrition "Salvador Zubirán", Vasco

de Quiroga 15., Mexico City 14000, Mexico

Full list of author information is available at the end of the article
} 


\section{Background}

Obesity is a worldwide public health issue, reaching epidemic condition in developing countries. Mexico has a $32.8 \%$ of adult obesity associated to malnutrition, increasing the incidence of hearth stroke, type 2 diabetes, cancer, premature death and inflammation [1]. Oxidative damage is another side effect of obesity, this physiological status occurs when endogenous system loses balance. Antioxidant activity from plant components regulates at some extent this imbalance by increasing the scavenging activity of reactive oxygen species (ROS) such as hydrogen peroxide $\left(\mathrm{H}_{2} \mathrm{O}_{2}\right)$. The inicial steps of development of degenerative diseases are preventing by protection of target molecules as lipids, proteins and nucleic acids from oxidative damage [2]. Many plants distributed in arid and semi-arid environments have alternative uses such as forage resources; traditional medicine and more recently, they have been pointed out as antioxidant sources [3-5], mainly due to their polyphenol content. These compounds have received attention because of their antioxidant capabilities and their protection against ROS-induced damage $[2,6]$ with biological functions like antiinflammatory, anticancer, antiobesity, antiaging [7], hepatoprotective and antidiabetic properties [8]. Acacia species are widely distributed in arid, semiarid and tropical regions of Mexico and all around the world. The extracts obtained from these plants have previously shown antimicrobial [3], antihelmintic [9] and antioxidant [4] properties.

Information of Acacia in terms of its antioxidant capacity is very limited; however Hannachi et al. [10] reported the protective response against 2,2' -azino-bis (3ethylbenzthiazoline-6-sulphonic acid) radical cation $(\mathrm{ABTS} \bullet+)$ and 1,1-diphenyl-2-picrylhydrazyl $\left(\mathrm{DPPH}^{+}\right)$ radicals $(0.78$ and $2.4 \mathrm{mM}$ trolox equivalents, respectively). They found a polyphenol content of $276 \mathrm{mg}$ gallic acid equivalents/100 g dry matter and identified the flavonoids gallic acid, methyl gallate, myricetin, naringenin, and quercetin in pods of this species.

Acacias have been found as a natural forage resource in these marginal regions. Improving the utilization of local vegetation for livestock production would let to increase the functional quality of animal products (milk, meat, and by-products), supporting a healthy and appropriate diet for human while promoting preventive actions aimed to reduce chronic maladies related to obesity.

The main goal of the present study was to determine the antioxidant activity and protection against oxidativeinduced damage of crude extracts of Acacia shaffneri and Acacia farnesiana pods. Secondly, we simulated the potential preventive influence of antioxidant compounds. Two experiments were performed: 1) the protective effect of crude extracts of Acacia pods were challenged against $\mathrm{H}_{2} \mathrm{O}_{2}$ using pig kidney LLC-PK1 cells in an in vitro assay; and 2) gerbils (Meriones unguiculatus) were employed in an in vivo model to observe the effect of crude extract of Acacia pods on the plasma antioxidant capacity.

\section{Methods \\ Reagents}

2,2'-azobis(2-amidinopropane dihydrochloride (AAPH; Sigma-Aldrich St. Louis, MO. USA. cat. 440914). Trolox (6-Hydroxy-2,5,7,8-tetramethylchroman-2-carboxylic acid; Calbiochem, Billerica, Massachusetts. U.S. cat. 648471). Fluorescein (Sigma-Aldrich St. Louis, MO. USA. cat. F6377). Dulbecco's Medium Modified (DMEM; Gibco BRL. Waltham, MA, USA. cat. 12800-017). Tryple Express (Gibco BRL Waltham, MA, USA. cat. 12604013). Fetal bovine serum (Gibco BRL Waltham, MA, USA. cat. 16000044). Penicillin/streptomycin (Gibco BRL Waltham, MA, USA. cat. 15140122). $\mathrm{H}_{2} \mathrm{O}_{2}$ (J.T. Baker Center Valley PA, USA. cat. 2186). 5(6)-carboxy-2',7'-dichlorodihydrofluorescein diacetate (carboxy- $\mathrm{H}_{2}$ DCFDA) (Molecular Probes Waltham, MA, USA. cat. C-400).

\section{Vegetal extracts obtention}

Vegetal samples evaluated in this study were collected in February of 2014 in the semiarid region of central Mexico at $20^{\circ} 35^{\prime}$ latitude North and $100^{\circ} 18^{\prime}$ longitude West within the Queretaro state. The place is 1950 masl with $460 \mathrm{~mm}$ of average precipitation per year. The person responsible for the botanical identification was Manuel Rivera, a staff member of the FES-Cuautitlan herbarium at the National Autonomous University of Mexico (UNAM). The internal identification number of the material is 8757 for $A$. farnesiana and 8765 for $A$. schaffneri. A. farnesiana and A. schaffneri pods were collected, managed and extracted (methanol:water, 80:20 v/ v) to obtain a crude extract, as described by Cuchillo et al. [3]. Total polyphenols were determined with the recommendations of the same authors.

\section{Antioxidant activity in vitro}

Free radical scavenging capacity of crude extracts of AF and AS pods was evaluated using the decoloration reduction of ABTS + assay from Re et al. [11]. An appropriate solvent blank reading was taken $\left(A_{\mathrm{B}}\right)$. After the addition of $100 \mu \mathrm{L}$ of ethanol extracts solution (200 ppm) to $3 \mathrm{ml}$ of ABTS + solution, the absorbance reading was taken at $30{ }^{\circ} \mathrm{C}$ for $10 \mathrm{~min}$ after initial mixing $\left(A_{\mathrm{E}}\right)$. All solutions were used on the day of preparation. The percentage of inhibition of ABTS + + was calculated using the following formula: \% scavenging activity $=\left[\left(A_{\mathrm{B}}-A_{\mathrm{E}}\right) / A_{\mathrm{B}}\right] \times 100$. Where $A_{\mathrm{B}}=$ absorbance of the blank, and $A_{\mathrm{E}}=$ absorbance of the crude extracts. Catechin and $\alpha$-tocopherol standards $(100 \mathrm{ppm})$ were used as references. 
Another assay to evaluate the antioxidant scavenging capacity for crude extracts of pods was done using $\mathrm{DPPH}^{+}$assay according to Von Gadow et al. [12] with some modifications. Briefly, $0.25 \mathrm{ml}$ of extract solution (200 ppm), were added to $2 \mathrm{ml} 0.36 \mathrm{mM} \mathrm{DPPH}^{\bullet}$ solution. The mixture was shaken vigorously and left stand for $30 \mathrm{~min}$ in the dark. The absorbance was measured at $513 \mathrm{~nm}$ at $t=0$ and after 30 min using a Beckman DU70 spectrophotometer. Radical scavenging activity was calculated according to the same equation used above. Butylated hydroxyanisole (BHA) and $\alpha$-tocopherol standards $(100 \mathrm{ppm})$ were used as references.

Liposomes were prepared according to Tsuda et al. [13]. Briefly, soy lecithin $(10 \mathrm{~g})$ was dispersed in a sodium phosphate buffer $(100 \mathrm{ml}, 20 \mathrm{mM}, \mathrm{pH}$ 7.4) and sonicated (Bioblock Scientific, Vibra cell, Newton, CT; USA) for $2.5 \mathrm{~h}$ in an ice-cold water bath. Crude extracts of AF and AS pods were tested for lipid peroxidation activity with the following mixture: extract $(0.5 \mathrm{ml}$, $200 \mathrm{ppm})$, liposomes $(2 \mathrm{ml}), 25 \mathrm{mM} \mathrm{FeCl}_{3}(0.1 \mathrm{ml})$, $25 \mathrm{mM} \mathrm{H}_{2} \mathrm{O}_{2}(0.1 \mathrm{ml}), 25 \mathrm{mM}$ ascorbic acid $(0.1 \mathrm{ml})$ and $0.2 \mathrm{M}$ phosphate buffer $(1.2 \mathrm{ml}, \mathrm{pH} 7.4)$. Mixture was incubated at $37^{\circ} \mathrm{C} / 4 \mathrm{~h}$ and $1 \mathrm{ml}$ of BHA $(20 \mathrm{mg} / \mathrm{ml}$ in methanol) was added to stop the reaction. Oxidation of liposomes was subsequently determined by measuring the thiobarbituric acid-reactive substances (TBARS) by adding thiobarbituric acid and $\mathrm{HCl}(1$ and $10 \%$, respectively, $1 \mathrm{ml}$ each) and heating the mixture $\left(100{ }^{\circ} \mathrm{C} /\right.$ $30 \mathrm{~min})$. Mixture was cooled in an ice bath $(15 \mathrm{~min})$ and $5 \mathrm{ml}$ of chloroform (J.T. Baker, $99.8 \%$ ) were added, then it was centrifuged $(3,000 \times \mathrm{g} / 20 \mathrm{~min})$. Absorbance of the supernatant was measured at $532 \mathrm{~nm}$ (Beckman DU-70 spectrophotometer). Control was prepared by adding ethanol instead of vegetal extract, and a blank without liposomes but methanol was also analyzed. Inhibition of TBARS formation (\%) was calculated with the following equation: $100 \times\left(A_{0}-A_{\mathrm{t}}\right) /\left(A_{0}-A_{1}\right)$ where $A_{0}, A_{1}$, and $A_{\mathrm{t}}$ are values for control, blank, and samples absorbance, respectively.

To evaluate the antioxidant activity in cells in culture, pig kidney cells LLC-PK1 (Lilly Laboratory Culture Porcine Kidney Type 1, obtained from American Type Culture Collection (Rockville, MD, USA) were employed. Cells were incubated in 48 well plates for $24 \mathrm{~h}$ under the following conditions: $37{ }^{\circ} \mathrm{C}, 5 \% \mathrm{CO}_{2} / 95 \%$ atmospheric air (NUAIRE-5820 incubator) in DMEM with $10 \%$ FBS for $24 \mathrm{~h}$. Then DMEM with FBS was replaced with $250 \mu \mathrm{L}$ of DMEM, and the incubation was set for another $30 \mathrm{~min}$, under the same conditions. Vegetal extracts solutions were added $(5 \mu \mathrm{L}$ of 2,500 or $10,000 \mathrm{ppm})$ to get final concentrations of 50 or $200 \mathrm{ppm}$ in half of wells, respectively, and plates were incubated for 30 additional minutes. An $\mathrm{H}_{2} \mathrm{O}_{2}$ solution $(12.5 \mu \mathrm{L}, 20 \mathrm{mM})$ was used as external oxidant; and it was added only to half of wells of each vegetal extract concentration in order to detect a possible pro-oxidant effect; and they were incubated for $2 \mathrm{~h}$. After discarding DMEM, all wells were washed with $250 \mu \mathrm{L}$ of phosphate buffer solution (PBS) at $37{ }^{\circ} \mathrm{C}$. After discarding it, a 6carboxy-2', $7^{\prime}$-dichlorodihydrofluorescein diacetate (carboxy- $\mathrm{H}_{2}$ DCFDA) solution was added $(250 \mu \mathrm{L}, 15 \mu \mathrm{M}$ in PBS). A final incubation of 20 min took place before replacing carboxy-H2DCFDA solution by cold DMEM $\left(250 \mu \mathrm{L}, 4{ }^{\circ} \mathrm{C}\right)$. All volumes mentioned were considered for each well and incubation conditions were always the same. Cells were observed to detect ROS presence in cytoplasm using an inverted microscope (Nikon Eclipse TS 100) under minimum illumination conditions with a regular lamp to detect cells and then, using different filters $(488 \mathrm{~nm}$ excitation and $530 \mathrm{~nm}$ emission for carboxy-DCF) to visualize fluorescence. Emission camps (brilliant green) were photographed and quantified using a NIS-Elements software (2.3 and 3.0, respectively) according to Hernández-Fonseca et al. [14].

\section{Antioxidant activity in vivo}

A total of 72 Mongolian gerbils (Meriones unguiculatus) males and females, pathogen-free, 10-18 weeks old, weight between 65-89 g originally purchased from Charles River Laboratories (Wilmington, MA, USA) were used and housed in polypropylene cages on hard wood chip bedding in groups of five-eight/cage. Food and water were provided ad libitum in a temperaturecontrolled room $\left(22 \pm 1{ }^{\circ} \mathrm{C}\right)$ with a 12-h light-dark cycle, and 40-60\% humidity in the specific pathogen-free animal facility at National Institute of Medical Science and Nutrition Salvador Zubirán.

Animals' adaptation period included physical contact twice a week during bedding change and weekly when weight was registered from two weeks before dosage onset to the end of the study. Protocols for maintenance, sample collections and euthanasia were reviewed and approved by the Institutional Animal Care and Research Advisory Committee (Comité de Investigación en Animales-CINVA).

Animals were randomly divided as follows: three doses groups (8, 16 and $32 \mathrm{mg}$ of total polyphenols (TP) /100 g body weight); one positive control group (0.5 mg ascorbic acid/100 g body weight); and one negative control group (acidified water, $\mathrm{HCl} 50 \mathrm{ppm}, \mathrm{pH}$ 2.4). Calculations were made in order to give $1.0 \mathrm{~mL} / 100 \mathrm{~g}$ body weight. The dose was given orally every day at 8:00 am using oral gavage needles made of stainless steel with a rounded-silver tip adjusted in a $1.0 \mathrm{~mL}$ syringe.

\section{Biochemical determinations in plasma}

In order to collect blood samples, an hour after last dosage, animals were anesthetized intraperitoneally with a 
ketamine/xylacine $\operatorname{mix}(7.0 / 0.8 \mathrm{mg} / 100 \mathrm{~g}$ weight, respectively). Once ocular and patellar reflexes were gone, cardiac puncture was done in a hair-free thoracic area to get at least $1 \mathrm{~mL}$ of blood in a Vacutainer blood collection tube with EDTA as anticoagulant.

$\mathrm{DPPH}^{+}$scavenging capacity was determined according to Koren et al. [15]: once plasma was obtained, two reaction tubes per sample were prepared with $25 \mu \mathrm{L}$ of saline, $25 \mu \mathrm{L}$ of plasma, and $50 \mu \mathrm{L}$ of $\mathrm{DPPH}^{+}$solution (1 $\mathrm{mmol} / \mathrm{L}$, light-protected). Blanks were prepared replacing plasma with $25 \mu \mathrm{L}$ of Hank's balance salt solution. All tubes were incubated for $2 \mathrm{~min}$ at room temperature in darkness, and $800 \mu \mathrm{L}$ of absolute ethanol were added, they were inverted few times for homogenization, and incubated for 2 additional minutes in same conditions. Tubes were centrifuged at $15,000 \times \mathrm{g}$ for $2 \mathrm{~min}$, absorbance of supernatant was measured at $517 \mathrm{~nm}$. Results were such as percent (\%) of $\mathrm{DPPH}^{+}$scavenged, calculated by the following formula: [(optical density of controloptical density of compound)/(optical density of control)*100]. Ascorbic acid was used as a reference compound [15].

Oxygen radical absorbance capacity (ORAC) assays were performed in a Synergy ${ }^{\text {ma }}$ HT Multi-Mode Microplate Reader (BioTek Instruments, Inc., Winooski, VT, USA) and were based on the method described by Huang et al. [16]. In these assays 2,2'-azobis-(2-amidinopropane dihydrochloride) (AAPH), a water-soluble azo compound, was used as a peroxyl radical generator; Trolox, a water-soluble vitamin $\mathrm{E}$ analogue, was used as standard. Briefly, $25 \mathrm{uL}$ of water, Trolox standards and diluted samples were mixed with $25 \mathrm{uL}$ of $153 \mathrm{mM}$ AAPH and with $150 \mathrm{uL}$ of $50 \mathrm{nM}$ fluorescein and incubated at $37{ }^{\circ} \mathrm{C}$. The fluorescence was measured every minute for 90 min using fluorescence filters for an excitation wavelength of $485 \mathrm{~nm}$ and an emission wavelength of $520 \mathrm{~nm}$. The ORAC values were calculated using the net area under the decay curves.

\section{Statistical analyses}

A descriptive analysis was done to know response distribution. An ANOVA analysis was used as nonparametric test using Kruskal-Wallis for all groups and U de Mann-Whitney for peers to detect differences among groups and doses with SPSS statistic software $\left(18^{\text {th }}\right.$ version, IBM Corporation, New York, USA). Differences were considered significant when $\mathrm{P} \leq 0.05$.

\section{Results}

In vitro assays

Total polyphenol content, antioxidant activity of crude extract of Acacia shaffneri and Acacia farnesiana pods

Total polyphenol content in A. farnesiana and A. schaffneri was 76 and 213 equivalents of gallic acid/g of extract. In Table 1, we observe that both pod extracts presented an important protective effect on radical scavenging capacity against ABTS $\bullet+$ and $\mathrm{DPPH}^{+}$, and also in TBARS formation. On ABTS + radical scavenging capacity no significant difference was found between extracts $(P>0.05)$. However, both extracts were significantly less effective ( $P$ $<0.05)$ than alpha-tocopherol and catechin standards. When extracts were tested using $\mathrm{DPPH}^{+}$no significant difference $(P>0.05)$ was found between them; neither when compared to alpha-tocopherol nor BHA standards. In relation to inhibition of TBARS formation in liposomes, extracts did show significant differences $(P>0.05)$ between them, but they were significantly different $(\mathrm{P}<0.05)$ when compared to alpha-tocopherol standard (Table 1).

According to the statistical assessment of the potential protection against oxidative-induced damage on kidney cells of crude extracts AS and AF pods, by a KruskalWallis test and the confirmatory U de Mann Whitney, we found that were not significant differences $(P>0.05)$ among extracts at $50 \mathrm{ppm}$ concentration and control. However, at $200 \mathrm{ppm}$ concentration of crude extract of AS and AF pods there were significant differences $(\mathrm{P}<$ $0.05)$ between extracts in relation to $\mathrm{H}_{2} \mathrm{O}_{2}$ and control cells, being crude extract of AF pods which presented the highest antioxidant protection capacity (Figs. 1, 2, and 3). We can also suggest that crude extracts of AS and AF pods at $200 \mathrm{ppm}$ concentration have no prooxidant effect since no cell damage was observed and the fluorescence signal was similar to those of the kidney cells in DMEM alone.

\section{Protection against oxidative-induced damage in porcine kidney cells of crude extracts of Acacia shaffneri and Acacia farnesiana pods}

As shown in Fig. 1, AS crude extract presented a protective effect of kidney cells against $\mathrm{H}_{2} \mathrm{O}_{2}$-induced

Table 1 In vitro antioxidant activity (\%) of crude extracts from Acacia shaffneri (AS) and Acacia farnesiana (AF) pods

\begin{tabular}{llllll}
\hline Free radicals & AS & AF & alpha-tocopherol & catechin & BHA \\
\hline ABTS•+ & $10.85^{\mathrm{b}} \pm 0.08$ & $10.47^{\mathrm{b}} \pm 0.36$ & $92.64^{\mathrm{a}} \pm 0.51$ & $91.99^{\mathrm{a}} \pm 1.00$ & $\mathrm{ND}$ \\
DPPH $^{\bullet}$ & $94.77^{\mathrm{a}} \pm 0.36$ & $95.18^{\mathrm{a}} \pm 0.26$ & $93.42^{\mathrm{a}} \pm 0.69$ & $\mathrm{ND}$ & $92.36^{\mathrm{a}} \pm 0.25$ \\
TBARS & $66.59^{\mathrm{b}} \pm 1.23$ & $66.05^{\mathrm{b}} \pm 1.62$ & $92.54^{\mathrm{a}} \pm 0.72$ & $\mathrm{ND}$ & $\mathrm{ND}$ \\
\hline
\end{tabular}

$A B T S \cdot+2,2^{\prime}$-azino-bis (3-ethylbenzthiazoline-6-sulphonic acid; $D P P H^{\bullet}$ 1,1-diphenyl-2-picrylhydrazyl; TBARS thiobarbituric acid reactive substances, $B H A$ buthylated hydroxyanisole; $N D$ not determined

${ }^{a, b}$ Means with different letters within the same row are significantly different at $\mathrm{P}<0.05$ 

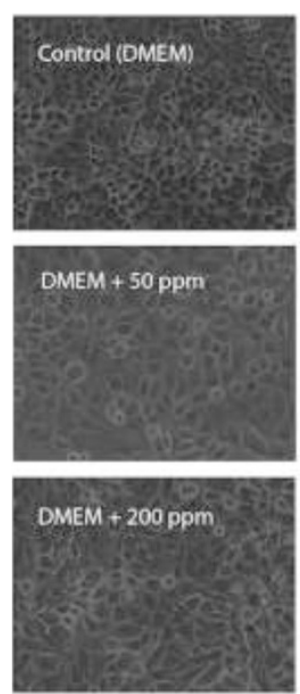
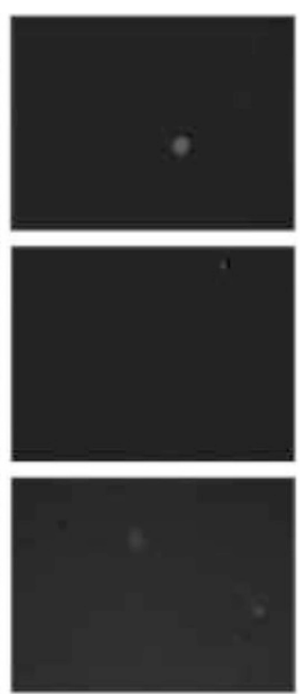
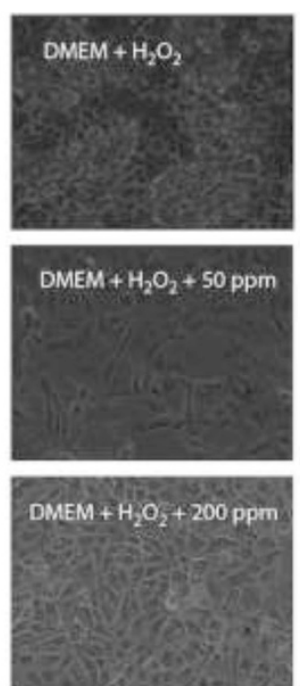
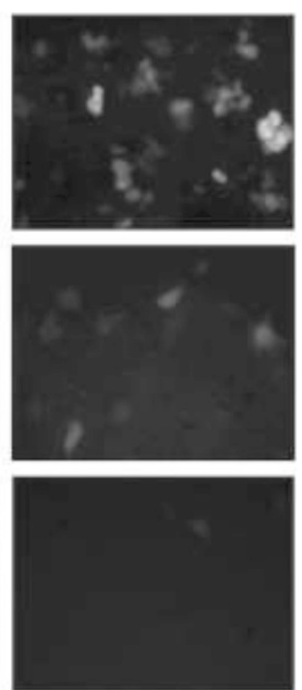

Fig. 1 Effect of 50 and 200 ppm of crude extract of Acacia shaffneri pods in porcine kidney cells cultivated in Dulbecco's modified eagle medium (DMEM) with or without $\mathrm{H}_{2} \mathrm{O}_{2}$

damage; either with 50 or 200 ppm concentrations. These results are clearly different from those obtained from DMEM alone or with $\mathrm{H}_{2} \mathrm{O}_{2}$, where cells lysis is certainly observed as brilliant green fluorescent spots. We also found that crude extrac of AS pods did not have prooxidant effect at the concentrations evaluated in this study. From Fig. 2, we observed that crude extract of AF pods presents similar antioxidant protective effect when defied against $\mathrm{H}_{2} \mathrm{O}_{2}$ as oxidative aggressor of kidney cells.

Figure 3 allows comparing this protective effect in a quantitative basis. Previously, we made sure that crude extract of both species pods did not induce any prooxidative effect on porcine kidney cells at none concentration evaluated in the present study. We can state that cells damage in DMEM with addition of $\mathrm{H}_{2} \mathrm{O}_{2}$ is significantly higher than those when crude extracts were added either at $50(\mathrm{P}<0.05)$ or $200 \mathrm{ppm}(\mathrm{P}<$ 0.001). In relation to AS compared to AF when added at $50 \mathrm{ppm}$ there was no difference $(P>0.05)$ between species when $\mathrm{H}_{2} \mathrm{O}_{2}$ was added as aggressor factor. However, at $200 \mathrm{ppm}$ AF showed a better protective effect than AS $(\mathrm{P}<0.05)$.
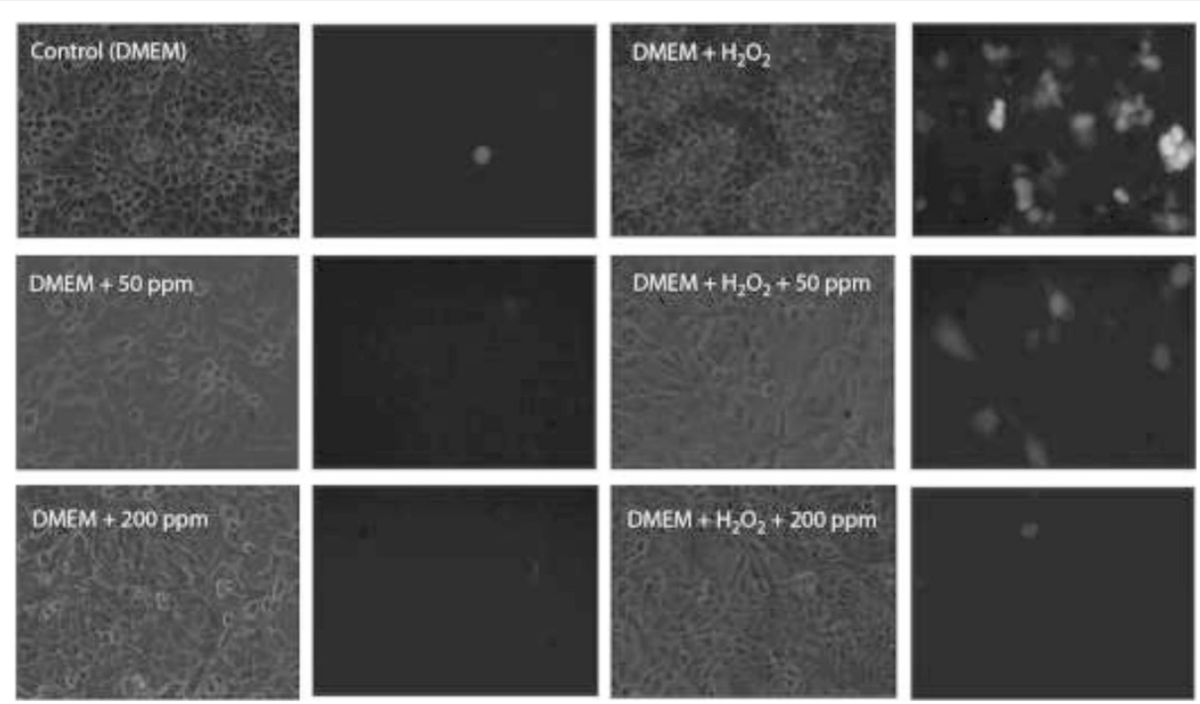
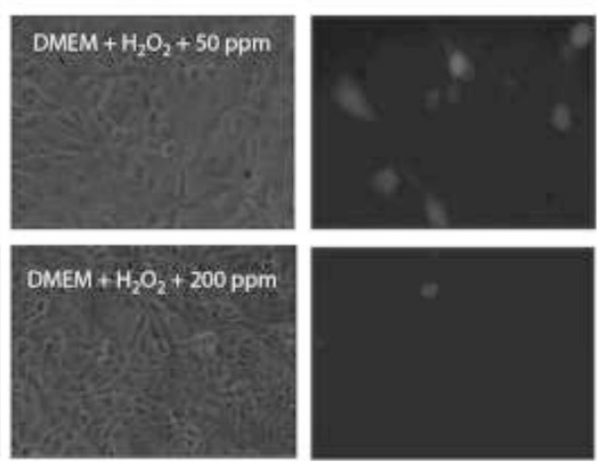

Fig. 2 Effect of 50 and 200 ppm of crude extract of Acacia farnesiana pods in porcine kidney cells cultivated in Dulbecco's modified eagle medium (DMEM) with or without $\mathrm{H}_{2} \mathrm{O}$ 


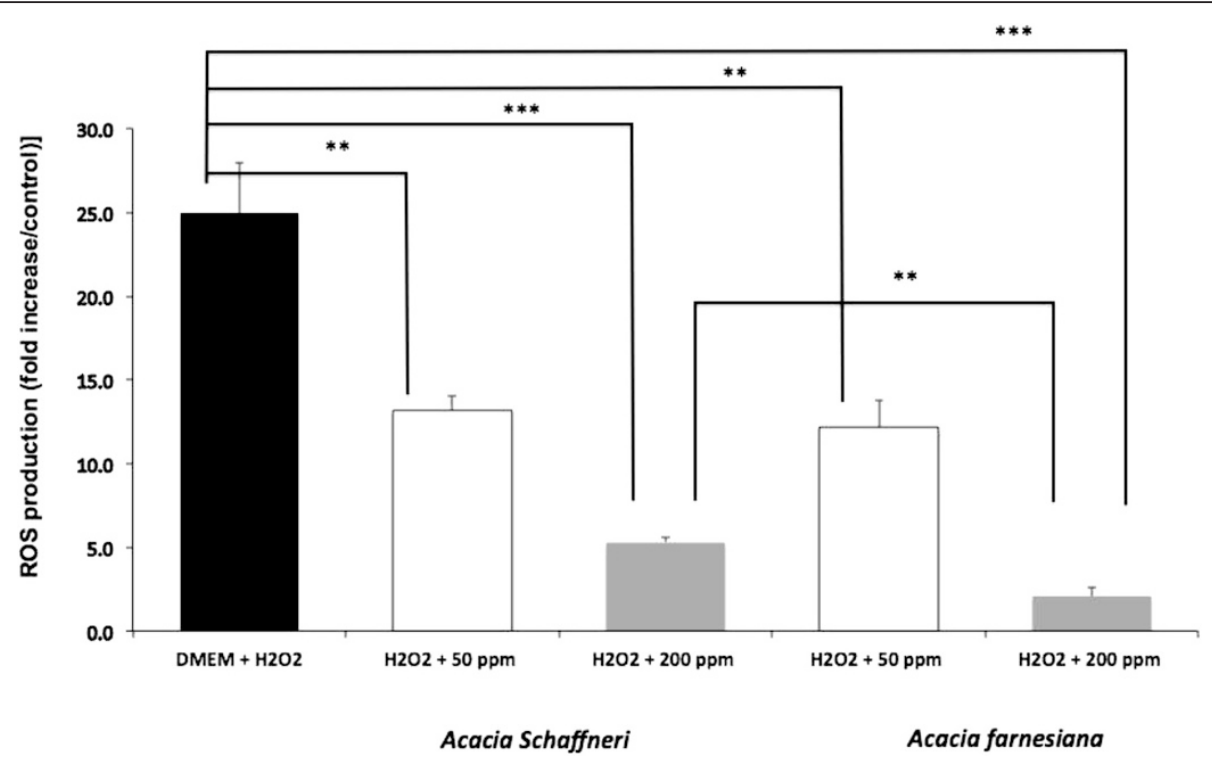

Fig. 3 Quantitative protection of crude extracts of Acacias pods in porcine kidney cells against $\mathrm{H}_{2} \mathrm{O}_{2}$-oxidative-induced damage at two different concentrations

\section{In vivo assay}

$\mathrm{DPPH}^{+}$scavenging capacity and ORAC of gerbil plasma with three different dosages of crude extract of Acacia shaffneri and Acacia farnesiana pods

Table 2 shows the effect of different concentrations of crude extracts of pods on $\mathrm{DPPH}^{+}$scavenging capacity and ORAC. As expected the highest concentration (32 mg/100 g BW) presented the best effect of both crude extracts (AF and AS) on $\mathrm{DPPH}^{+}$and ORAC. As extracts of 16 and $32 \mathrm{mg} / 100 \mathrm{~g} \mathrm{BW}$ doses were no significantly different $(P>0.05)$ from positive control $(C+$, ascorbic acid), it is important to point out that a lower concentration of AF and AS showed higher scavenging capacity than dose from basal and negative control (C-, acidified water) groups on both assays. For ORAC results, AS extracts $(8,16$, and $32 \mathrm{mg} / 100 \mathrm{~g} \mathrm{BW})$ showed the highest values among all groups, even when compared to $\mathrm{C}+$ group. On the other hand, when AF was administered in a concentration of $32 \mathrm{mg} / 100 \mathrm{~g} \mathrm{BW}$, presented no significant difference $(P>0.05)$ from $C_{+}$ group and lower concentrations of AF showed higher values when compared to basal group.

\section{Discussion}

Obesity condition has multiple side effects incluiding cell oxidative damage resulting in many cases in chronic maladies. Such diseases could be preventible at some extent by hindering the initial process from oxidative damage caused by reactive oxygen species [2]. Some of the compounds being part of the phytochemical group responsible for these desirable effects are the polyphenols. Total polyphenol content in the present study was in accordance with the results reported previously by Singh et al. [17] with values ranging from 19 to $657 \mathrm{mg}$ of gallic acid equivalents/g of extract whereas Singh et al. [18] reported values for $A$. auriculiformis from 300, 495 and $775 \mathrm{mg}$ of gallic acid equivalents/g in crude extract, ethyl acetate and water fractions, respectively. Acacia genus is recognized as a rich source of phytochemicals however, Acacia profiling has not been subject to

Table 2 Effect of different concentrations (8, 16 and $32 \mathrm{mg}$ TP/100 g BW) of crude extracts of Acacia farnesiana (AF) and Acacia shaffneri (AS) pods on $\mathrm{DPPH}^{\bullet}$ scavenging capacity (\%) and oxygen radical absorbance capacity (ORAC) ( $\mu \mathrm{M}$ Trolox equivalents/L) of gerbil (Meriones unguiculatus) plasma

\begin{tabular}{|c|c|c|c|c|c|c|c|c|c|}
\hline \multirow[t]{2}{*}{ Vegetal extract } & \multicolumn{3}{|l|}{$\mathrm{AF}$} & \multicolumn{3}{|l|}{ AS } & \multirow[t]{2}{*}{ Basal } & \multirow[t]{2}{*}{${ }^{*} \mathrm{C}-$} & \multirow[t]{2}{*}{${ }^{* *} \mathrm{C}+$} \\
\hline & 8 & 16 & 32 & 8 & 16 & 32 & & & \\
\hline$\overline{\mathrm{DPPH}^{\bullet}}$ & $21.8^{d} \pm 2.4$ & $20.0^{\mathrm{e}} \pm 1.7$ & $30.0^{a} \pm 2.0$ & $22.2^{d} \pm 3.4$ & $26.2^{c} \pm 2.1$ & $29.0^{b} \pm 1.7$ & $14.9^{f} \pm 2.4$ & $14.7^{f} \pm 2.4$ & $26.1^{c} \pm 1.6$ \\
\hline ORAC & $1339^{d} \pm 246$ & $1309^{d} \pm 102$ & $1561^{c} \pm 156$ & $2390^{\mathrm{a}} \pm 569$ & $2245^{a} \pm 550$ & $2207^{a} \pm 441$ & $1090^{e} \pm 88$ & $1213^{d} \pm 166$ & $1888^{b} \pm 223$ \\
\hline
\end{tabular}

$B W$ body weight; $D P P H^{\bullet}$ 1,1-diphenyl-2-picrylhydrazyl radical

${ }^{*} \mathrm{C}$ - = negative control (acidified water)

** $\mathrm{C}+=$ Positive control (ascorbic acid, $0.5 \mathrm{mg} / 100 \mathrm{~g} \mathrm{BW}$ )

$a, b, c, d, e, f$ Means with different letters within the same row are significantly different at $P<0.05$ 
complete study. To our knowledge, few studies have investigated extensively in this respect. Therefore it is recommended to identify bioactive compounds in further investigations of the extracts to isolate, to purify and to test them to suggest specific applications and/or recommendations.

Acacia pod extracts showed a protective effect on radical scavenging capacity against $\mathrm{ABTS} \bullet+, \mathrm{DPPH}^{+}$, and TBARS formation in vitro. A previous study had reported a functional bioactive compound in A. farnesiana [3] as methyl gallate and Crispo et al. [6] suggested that methyl gallate can significantly attenuate the apoptotic response as a result of a long-term oxidative stress, atenuanting this process throught direct and indirect scavenging of reactive oxygen species (ROS). Our results on crude pod extracts did not induce pro-oxidative effects when added to porcine kidney cells in DMEM. Cells damage in DMEM with addition of $\mathrm{H}_{2} \mathrm{O}_{2}$ was significantly lower when pod extracts were added at $200 \mathrm{ppm}$ than when added at $50 \mathrm{ppm}$. Maldini et al. [19] reported the presence of strong antioxidant polyphenols constituents in A. nilotica pods which were evaluated employing trolox equivalent antioxidant capacity (TEAC) assay; where a strong free radical scavenging activity on ABTS + cation was showed. The presence of different derived galloylated of catechin and gallocatechin are compounds with antioxidant properties. Some of these compounds recently reported in the genus Acacia as gallic acid methyl ester-4-gallate, gallocatechin-7,3'digallate, gallocatechin-7,4'-digallate and 1,3-di-O-galloyl- $B$-D-glucopyranose, could be further found in our extracts. It is important to notice that higher polyphenol content from $A$. shaffneri did not was related to higher protection against the oxidative stress damage by $\mathrm{H}_{2} \mathrm{O}_{2}$ since porcine kidney cells showed a lower oxidative damage when crude extact of $A$. farnesiana was added. This suggests that some other compounds that were not considered in this study could be responsible for such radical scavenging activity. Ramli et al. [20] evaluated the antioxidant activity of ethanolic extract of $A$. farnesiana leaves, on scavenging $\mathrm{DPPH}^{+}$radical, showing a $80 \%$ of activity with $100 \mu \mathrm{g} / \mathrm{ml}$, which is lower than the $95.2 \%$ obtained in the present study, with a concentration of an methanol:water extract of $200 \mu \mathrm{g} / \mathrm{ml}$ in pods. On the other hand, previous unpublished assays in leaves (AF) and whole plant (AS; leaves, stems and pods) $\mathrm{MeOH}: \mathrm{H}_{2} \mathrm{O}(80: 20 \mathrm{v} / \mathrm{v})$ extracts, with same concentration $(200 \mu \mathrm{g} / \mathrm{ml})$ showed a $\mathrm{DPPH}^{+}$radical scavenging activity of 95.1 and $94.8 \%$, respectively. We reported [4] an important polyphenol content in A. farnesiana (AF) complete plant $(38,170 \mathrm{mg}$ gallic acid equivalents/kg dry matter). Many other compounds in AF have been reported such as flavonoids (12 $\mathrm{mg}$ rutin equivalents/100 g dry matter), carotenoids, coronaric, oleic, linoleic and linolenic acids, and some aldehydes (geraniol and geranyl acetate) $[3,6,21]$.

The oral administration of rich-polyphenol extracts increased plasma free radical scavenging properties and presented an important dose-dependent positive effect in those groups where Acacia pod extracts were dispensed. Haruenkit et al. [22] reported the protective antioxidant effect of natural products from exotic tropical fruits in plasma rats fed with 1 and/or $5 \%$ of durian, snake and mangosteen fruits, showed a similar antioxidant activity (28.1, 21.1 and $10.5 \%$, respectively) when compared to antioxidant activity from gerbil plasma which were dosified with 8,16 and $32 \mathrm{mg}$ of total polyphenols/100 g of BW with extract pods from $A$. farnesiana $(21.8,20.0$ and $30.0 \%$ ) and from A. Schaffneri (22.2, 26.2 and $29.0 \%$, respectively). This response was likely related to the phytochemicals compounds mainly polyphenols $[2,19]$ as ferulic acid and its metabolites can increase radical scavenging properties of plasma in rats after the ingestion of this compound in the diet [23, 24]. Nevertheless, supra-physiological concentrations of certain polyphenols can potentially interfere with many disease-related biochemical processes acting as prooxidants [6]. Both species evaluated in the present study showed resemble antioxidant activity in vitro whereas AF presented the best protective capacity in vivo. However, larger abundance of Acacia and wide distribution of AF along the Mexican territory, suggests that this species could be a more important source of bioactive compounds than AS.

\section{Conclusions}

The antioxidant protection of the acacia pods extracts reported in this study suggests the possible transference of antioxidant components and protective effects to animal products (milk, meat, and by-products) from Acacia pods. The incorporation of these non-conventional resources in ruminant feeding should be further evaluated. Profiling of Acacia farnesiana pods extract is necessary to identify responsible bioactive compounds of the showed antioxidant and protective properties.

\section{Competing interests \\ The authors declare that they have no competing interests.}

\section{Authors' contributions}

CDP and MCH designed and supervised all experimental phases of the study. Likewise, collected, interpreted data and wrote the manuscript. MDM and JALS performed in vivo experiment, animal care, animal housing, blood sampling, collected data and performed literature. OMC performed the radical scavenging assays in plasma, collected data and interpreted results. JGEM and EMJ performed the experiments using LLC-PK1 cells and collected data. MAAl performed statistical test and interpreted data analysis. JPC supervised the experiments using LLC-PK1 cells, revised, reorganized, interpreted data and wrote the manuscript. All authors read and approved the final version of the manuscript. 


\section{Acknowledgements}

We acknowledge to the animal nutrition department "Fernando Pérez-Gil Romo" of the National Institute of Medical Science and Nutrition Salvador Zubirán for the finantial support. We specially thank Sara Montaño Benavides for the technical support during the performance of the alcoholic plant extracts and for the assistance developing the in vitro experiments.

\section{Author details}

'National Institute of Medical Science and Nutrition "Salvador Zubirán", Vasco de Quiroga 15., Mexico City 14000, Mexico. ${ }^{2}$ Department of Biology, Faculty of Chemistry, National Autonomous University of Mexico, Mexico City 04510, Mexico. ${ }^{3}$ Faculty of Chemistry, National Autonomous University of Mexico, Mexico City 04510, Mexico.

Received: 13 June 2015 Accepted: 8 December 2015 Published online: 15 December 2015

\section{References}

1. Food and Agriculture organization of the United Nations (FAO). The estate of food and agricultura. Food Systems for Better Nutrition. Roma, Italy: FAO; 2013

2. Fernandez-Panchon MS, Villano D, Troncoso AM, Garcia-Parrilla MC. Antioxidant activity of phenolic compounds: from in vitro results to in vivo evidence. Crit Rev Food Sci. 2008. doi:10.1080/10408390701761845.

3. Sánchez E, Heredia N, del Camacho-Corona MR, García S. Isolation, characterization and mode of antimicrobial action against Vibrio cholerae of methyl gallate isolated from Acacia farnesiana. J Appl Microbiol. 2013. doi: 10.1111/jam.12328.

4. Cuchillo HM, Puga DC, Wrage-Mönning N, Espinosa MJG, Montaño BS, Navarro-Ocaña A, et al. Chemical composition, antioxidant activity and bioactive compounds of vegetation species ingested by goats on semiarid rangelands. J Anim Feed Sci. 2013;22(2):106-15.

5. Rahaman MS, Chaudhry MA. Evaluation of antioxidant and hepatoprotective effect of Acacia modesta wall against paracetamol induced hepatotoxicity. Brit J Pharma Res. 2015. doi:10.9734/BJPR/2015/15559.

6. Crispo JAG, Piché M, Ansell DR, Eibl JK, Tai IT, Kumar A, et al. Protective effects of methyl gallate on $\mathrm{H} 2 \mathrm{O} 2$-induced apoptosis in $\{\mathrm{PC1}\}$ cells. Biochem Bioph Res Co. 2010. doi:10.1016/j.bbrc.2010.02.079

7. Siriwardhana N, Kalupahana NS, Cekanova M, LeMieux M, Greer B, MoustaidMoussa N. Modulation of adipose tissue inflammation by bioactive food compounds. J Nutr Biochem. 2013. doi:10.1016/j.jnutbio.2012.12.013.

8. Sathya A, Siddhuraju P. Protective effect of bark and empty pod extracts from Acacia auriculiformis against paracetamol intoxicated liver injury and alloxan induced type $\{\|\}$ diabetes. Food Chem Toxicol. 2013. doi:10.1016/j. fct.2013.02.031.

9. Alonso-Díaz MA, Torres-Acosta JF, Sandoval-Castro CA, Capetillo-Leal CM. Polyphenolic compounds of nutraceutical trees and the variability of their biological activity measured by two methods. Trop Subtrop Agroecosyst. 2010;12:649-56.

10. Hannachi $\mathrm{H}$, Elfalle W, Ennajeh I, Laajel M, Khouja ML, Ferchichi A, et al. Chemicals profiling and antioxidants activities of Acacia seeds. J Med Plants Res. 2011. doi:10.5897/JMPR11.1390.

11. Re R, Nicoletta P, Anna P, Ananth P, Min Y, Catherine R-E. Antioxidant activity applying an improved ABTS radical cation decolorization assay. Free Radical Biol Med. 1999. doi:10.1016/S0891-5849(98)00315-3.

12. Von Gadow A, Joubert E, Hansmann CF. Comparison of the antioxidant activity of aspalathin with that of other plant phenols of rooibos tea (Aspalathus linearis), alpha-tocopherol, BHT, and BHA. J Agric Food Chem. 1997. doi:10.1021/jf960281n.

13. Tsuda TM, Watanabe K, Ohshima S, Norinobu SW, Choi Kawakishi S, Osawa T. Antioxidative activity of the anthocyanin pigments cyanidin 3-O-B-D-dlucoside and cyanidin. J Agric Food Chem. 1994 doi:10.1021/jf960281n

14. Hernández-Fonseca K, Cárdenas-Rodríguez N, Pedraza-Chaverri J, Massieu L. Calcium-dependent production of reactive oxygen species is involved in neuronal damage induced during glycolysis inhibition in cultured hippocampal neurons. J Neurosci Res, 2008. doi:10.1002/jnr.21634.

15. Koren E, Kohen R, Ginsburg I. Polyphenols enhance total oxidant scavenging capacities of human blood by binding to red blood cells. Exp Biology Med. 2010. doi:10.1258/ebm.2010.009370.
16. Maldonado PD, Rivero-Cruz I, Mata R, Pedraza-Chaverri J. Antioxidant activity of a-type proanthocyanidins from Geranium niveum (Geraniaceae). J Agric Food Chem. 2005. doi:10.1021/jf0483725.

17. Huang D, Ou B, Hampsch-Woodill M, Flanagan JA, Prior RL. Highthroughput assay of oxygen radical absorbance capacity (ORAC) using a multichannel liquid handling system coupled with a microplate fluorescence reader in 96-well format. J Agric Food Chem. 2002. doi:10. 1021/jf0201529.

18. Singh $B N$, Singh $B R$, Singh RL, Prakash D, Sarma BK, Singh HB. Antioxidant and anti-quorum sensing activities of green pod of Acacia nilotica L. Food Chem Toxicol. 2009. doi:10.1016/j.fct.2009.01.009.

19. Singh $R$, Singh $S$, Kumar $S$, Arora $S$. Free radical-scavenging activity of acetone extract/fractions of Acacia auriculiformis A. Cunn Food Chem. 2007. doi:10.1016/j.foodchem.2006.10.056.

20. Maldini M, Montoro P, Hamed Al, Mahalel UA, Oleszek W, Stochmal A, et al. Strong antioxidant phenolics from Acacia nilotica: profiling by ESI-MS and qualitative-quantitative determination by LC-ESI-MS. J Pharm Biomed Anal. 2011. doi:10.1016/j.jpba.2011.05.019.

21. Ramli S, Harada K, Ruangrungsi N. Antioxidant, antimicrobial and cytotoxicity activities of Acacia farnesiana (L.) Willd. Leaves ethanolic extract. Phcog J. 2011. doi:10.5530/pj.2011.23.8.

22. Seigler DS. Phytochemistry of Acacia-sensu lato. Biochem Syst Ecol. 2003. doi.org/10.1016/S0305-1978(03)00082-6

23. Haruenkit R, Poovarodom S, Leontowicz H, Leontowicz M, Sajewicz M Kowalska T, et al. Comparative study of health properties and nutritional value of durian, mangosteen, and snake fruit: experiments in vitro and in vivo. J Agric Food Chem. 2007. doi:10.1021/jf070475a.

24. Wang J, Sun B, Cao Y, Wang C. Wheat bran feruloyl oligosaccharides enhance the antioxidant activity of rat plasma. Food Chem. 2010. doi:10. 1016/j.foodchem.2010.05.033

\section{Submit your next manuscript to BioMed Central and we will help you at every step:}

- We accept pre-submission inquiries

- Our selector tool helps you to find the most relevant journal

- We provide round the clock customer support

- Convenient online submission

- Thorough peer review

- Inclusion in PubMed and all major indexing services

- Maximum visibility for your research

Submit your manuscript at www.biomedcentral.com/submit 